\title{
HUBUNGAN ANTARA KEPUASAN DENGAN KESETIAAN PASIEN (SURVEY PADA PASIEN BAGIAN JANTUNG RUMAH SAKIT INTERNASIONAL BINTARO TANGERANG)
}

\author{
Henry Eryanto*
}

\begin{abstract}
This research was airned at describing connections between: 1) The Quality of Services to the Patient Loyalty, 2) The Satisfaction, all together, to the patient loyalty. This study was held in the Bintaro International Hospital, Tangerang. The method of research is survey method. The population consist of all internal disease patients of Bintaro International Hospital, Tangerang. Sample of research are 40 patients which were taken by random sampling method. The result of research, that the service quality and the patient saticfaction themselves or all together, giving significant result toward the patient loyalty. The attitude towards the improvement quality of services, and patient satisfaction need to be trained for the employees of Bintaro International Hospital. This matter cannot be separated from the employees recruitment. Specifically for the best services for their patients, besides that matters the hospital management must be improved their tools and equipment that they're used, and would be hold the trainings for their employees.
\end{abstract}

Keywords: quality of services, patient loyalty, satisfaction,

\section{PENDAHULUAN}

Kesehatan memegang peran yang sangat penting dalam proses peningkatan kuatitas sumber daya manusia. Peningkatan kualitas kesehatan merupakan suatu proses yang terintegrasi dengan proses peningkatan sumber daya manusia itu sendiri. Menyadari pentingnya peningkatan sumber daya manusia, maka pemerintah bersama kalangan swasta sama-sama berupaya

Drs. Henry Eryanto, MM. Adalah Dosen Fakultas Ekonomi, Universitas Negeri Jakarta. meningkatkan kualitas sumber daya manusia melalui pembangunan kesehatan yang berkualitas.

Dalam Upaya mencapai derajat kesehatan yang optimal hal ini tidak lepas dari peranan rumah sakit sebagai unsur pelaksana di bidang pelayanan kesehatan. Rumah sakit sebagai ujung tombak yang berhadapan langsung dengan penderita atau pasien yang memerlukan bantuan pelayanan kesehatan harus dapat memberikan pelayanan yang berkualitas. 
Peran serta masyarakat dalam upaya memberikan pelayanan kesehatan melaui rumah sakit swasta sangat diharapkan, hal ini terlihat dengan dikeluarkannya peraturan Menteri Kesehatan Republik Indonesia Nomor: 920/Men.Kes/Per/XIII/1986 tentang upaya Pelayanan Kesehatan Swasta di bidang medic sebagai pengganti Peraturan Menteri Kesehatan Republik Indonesia Nomor: 532/Men. Kes/Per/XI/1982 yang dipandang tidak memadai lagi.

Untuk memperjelas peran masyarakat dalam upaya memberikan pelayanan kesehatan terlihat pada peraturan Menteri Kesehatan Republik Indonesia tersebut bahwa "peran serta masyarakat swasta secara merata, terjangkau dan dapat diberika oleh masyarakat sesuai dengan sistem kesehatan nasional semakin meningkat dan berkembang" (Peraturan Menteri Kesehatan Republik Indonesia 1986-920).

Upaya memenuhi tuntutan masyarakat pengguna jasa pelayanan kesehatan telah dilakukan oleh pihak rumah sakit sebagai pemberi jasa keseahtan dengan menawarkanberabgai paket dan program pelayanan kesehatan, selain menyediakan sarana dan prasarana yang canggiih serta berkualitas baik.

Berdasarkan kenyataan ini, pihak rumah sakit swasta yang ingin berkembang atau paling tidak bertahan hidup harus dapat meberikan kepada pasien berupa jasa pelayanan yang bermutu lebih baik, harga lebih murah dari para pesaingnya. Apabila pasien merasa tidak puas atau mutu pelayanan yang diberikan oleh pihak rumah sakit tersebut maka mereka akan pindah rumah sakit lain yang dapat memberikan pelayanan lebih bermutu dan kepuasan yang jauh lebih baik.

Karena itu agar suatu rumah sakit bias bertahan sekaligus memenangkan persaingan tersebut, maka mereka harus memiliki pasien yang setia (customer loyalty). Memiliki pasien yang setia merupakan dambaan dari setiap rumah sakit, keinginan seperti ini sebenarnya tidak hanya dambaan rumah sakit melainkan keinginan semua perusahaan. Baik perusahaan barang maupun perusahaan jasa, keduanya berusaha mendapatkan pelanggan yang setia apalagi di era tingkat persaingan yang bukan saja sekedar kompetitif namun sudah hiper kompetitif, pelanggan yang ssetia menjadi sumber kehidupan bagi perusahaan sehingga dapat terus berkembang hidup.

Menciptakan kesetiaan para pasien rumah sakit menjadi inti kegiatan bagi setiap rumah sakit menjadi inti kegiatan bagi setiap rumah sakit. Tetapi untuk mewujudkan hal ini tidaklah semudah yang diduga. Sekarang ini banyak pasien yang semakin kritis terhadap mutu pelayanan kesehatan yang mereka terima. Hal ini terlihat dengan banyaknya tulisan pembaa 
Koran atau majalah yang membahas tentang pelayanan suatu rumah sakit. Keluhan ini umumnya tentang pelayanan awal, sikap perawat, dan dokter dalam menangani pasien, sarana yang tersedia, kelengkapan obat-obatan, kebersihan dan pada akhirnya pasien akan pindah ke rumah sakit lain yang meberikan pelayanan yang lebih baik.

Oleh sebab itu berbagai kegiatan dan program yang diselenggarakan oleh rumah sakit yang berusaha untuk mendapatkan pasien yang setia, bukanlah suatu upaya yang sia-sia. Bagi pihak rumah sakit ada bebeerapa keuntungan yang didapat dengan memiliki pasien yang setia, salah satunya adalah berkurangnya biaya operasional. Karena sebenarnya untuk mendapat pasien baru, pihak rumah sakit harus mengeluarkan biaya seperti biaya promosi dan biaya lainnya. Sedangkan untuk mempertahankan pasien yang setia tentunya tidak sebesar biaya untuk menarik pasien baru.

Untuk itulah maka rumah sakit harus melakukan reformasi program demi mendapatkan pasien yangs etia. Berbagai cara yang dilakukan oleh pihak rumah sakit dalam rangka membuat pasien setia umpamanya dengan program khusus seperti persalinan, medical chek up, dengan harga yang lebih murah. Menyediakan ruang dan tempat tidur, ruangan operasi, ruangan bersalin dan laboratorium yang semuanya berstandar internasional. Selain itu juga mereka menyediakan tenaga dokter umum dan dokter spesialis serta tenaga paramedis yang berpengalaman. Selain upay-upaya tersebut diatas yang terpenting pihak penyelenggara rumah sakit dari semua tingkatan kelas harus menerapkan sistem pelayanan sesuai dengan standar mutu pelayanan yang ditetapkan oleh Direktorat Jenderal Pelayanan Medik Departement Kesehatan Republik Indonesia.

Hal lain yang juga dapat menimbulkan kesetian pasien pada sebuah rumah sakit adalah rasa kebanggaan dan daya tarik pada nama besar atau brand image. Jadi dengan demikian brand (merek) termasuk faktor penentu dan penting dalam situasi persaingan yang ketat. Pada persaingan yang kian kental dewasa ini, brand atau merek mempunyai peranan penting. Penyebabnya, antara lain karena konsumen semakin bingung akan banyaknya merek (Taufik, 1997: 43).

Aspek kepuasan konsumen atau dikenal dengan program Customer Satisfation menjadi aspek yang harus mendapat perhatian dilingkungan penyelenggara rumah sakit pada umumnya, khususnya rumah sakit swasta. Hal ini dikarenakan bahwa sebenarnya bidang medis merupakan bidang jasa, dengan sendirinya faktor pelayanan menjadi kegiatan utama. Tentunya pelayanan disini bukan sekedar pelayanan biasa tetapi pelayanan yang bermutu baik 
menurut standar yang telah ditetapkan maupun pelayanan bermutu menurut keinginan konsumen dalam hal ini para pasien yang menggunakan jasa pelayanan dari sebuah rumah sakit.

\section{Kajian Teori \\ Kesetiaan Pasien}

Untuk definisi pasien cukup dari definisi umum yang telah dipahami oleh masyarakat. Dalam Kamus Umum Bahasa Indonesia yang dimaksud dengan pasien adalah "orang yang sakit yang dirawat di rumah sakit atau dokter". Kesetiaan seorang pasien rumah sakit umumnya tidak terlepas dari nama rumah sakit. David A. Aaker dalam bukunya Managing Brand Equity, mengungkapkan bahwa sebuah produk (baik barang maupun jasa) untuk bertahan di pasar yang kompetitif, tidak bisa dilepaskan tanpa merek (brand). Karenanya, bagi sebuah produk memiliki ekuitas merek (brand equity) menjadi tolak ukur yang harus diperhatikan oleh setiap rumah sakit. Tingkat tertinggi dari ekuitas merek, adalah kesetiaan terhadap merek (brand loyality). Dalam hal ini, kita dapat mengartikan kesetiaan pasien sebenarnya adalah kesetiaan pasien tersebut terhadap merek/nama pada suatu rumah sakit.

$$
\text { Dalam buku Strategi }
$$

Pemasaran, (Fandy Tjiptono, 1997: 36) membahas secara rinci tentang strategi kepuasan pasien. Kesimpulan pembahasan kepuasan pasien tersebut adalah bahwa kepuasan pasien akan bermuara kepada kesetiaan pasien. Kesetiaan diartikan sebagai "suatu variabel yang disebabkan oleh kombinasi dari kepuasan pasien, rintangan birokrasi (switching barriers) dan keluhan (voice). Artinya kesetiaan pasien tercipta karena kepuasan yang dirasakan pasien atas pelayanan yang diterimanya. Selain itu pula rintangan yang diciptakan oleh birokrasi dengan semakin dipermudahnya prosedur atas pelayanan akan membantu terciptanya nilai kesatiaan.

Demikian halnya dengan keluhan, semakin diperkecil keluhan dari pasien dengan memberikan pemecahan dari masalah, maka pasien yang mengeluh akan merasa dipenuhi tuntutannya dan merasa puas dari pemecahan tersebut.

Kesetiaan pasien bagi rumah sakit sangat penting karena pasien sebagai sumber dana sebuah rumah sakit yang dapat menciptakan nilai kesetiaan para pasiennya atau paling tidak dapat meyakinkan pasien agar tetap menjadi pasien, adalah rumah sakit yang telah memiliki salah satu keunggulan bersaing.

Ada beberapa keuntungan yang didapat dengan memiliki pasien yang setia diantaranya adalah: mendapatkan pasien baru lewat komunikasi dari mulut ke mulut, dapat mengurangi biaya pemasaran, meraih pasien dalam jumlah yang tinggi. 
Dan yang pasti, keunggulan sebuah rumah sakit yang memiliki pasien yang setia dapat membantu kelangsungan hidup rumah sakit. Karena pasien yang setia, tidak akan mudah berpindah ke rumah sakit lainnya, walaupun mereka diiming-imingi bermacam-macam.

\section{Kepuasan Pasien}

Pengetahuan

tentang perilaku pasien sebagai konsumen rumah sakit meliputi: siapakah yang menjadi pasien atau konsumen, kapankah mereka membutuhkan jasa pelayanan rumah sakit, mengapa mereka memutuskan untuk memilih suatu rumah sakit dan bukan rumah sakit lainnya, bagaimana mereka memutuskan dan menggunakan jasa pelayanan rumah sakit, serta faktor-faktor apa yang berperan dalam mempengaruhi pasien sebagai konsumen sebelum, selama dan setelah membeli suatu jasa pelayanan rumah sakit.

Hal ini tentunya harus menjadi perhatian serius dari para pengelola rumah sakit dalam memberikan jasa pelayanan. Karena jasa adalah suatu perbuatan, kinerja atau usaha yang dibeli oleh pasien sebagai pelanggan. Diharapkan dengan perhatian serius ini pasien akan membicarakan kepuasan atas jasa pelayanan tersebut, sebagai suatu ekspresi dari kejiwaan pasien.

Dapat diambil kesimpulan bahwa untuk menyatakan suatu pelayanan itu memuaskan, dapat dirasakan oleh pasien dengan beberapa tahap. Tahap pertama, harapan sebelum menggunakan (prepurchase expectations), pasien mencari atau mengevaluasi layanan yang akan digunakan. Pada tahap ini ia akan mencari apa yang ada pada ingatannya yang tersimpan dalam memori. Ketika dia menyadari belum menggunakan layanan ini, maka ia mulai mencari informasi yang beredar, baik yang diciptakan oleh rumah sakit atau dari pihak luar rumah sakit. Kemudian, ia memasuki tahapan kedua, yaitu persepsi proses kualitas (perceived process quality). Tahap ini merupakan proses penggunaan dan sekaligus evaluasi. Setelah hal ini berakhir, ia akan memasuki tahap selanjutnya, yaitu persepsi hasil kualitas (perceived output quality). Pada tahap ketiga inilah pasien mengevaluasi pengalamannya saat penggunaan jasa telah selesai. Dalam hal ini, pasien akan puas (Satisfactory quality), bila persepsi mereka bernilai sama dengan harapannya (expectations met), jika persepsi melebihi harapan (expectations exceeded), pasien akan merasa lebih puas (ideal quality); dan sebaliknya bila harapan melebihi persepsi (expectations not met), pasien tidak puas bahkan timbul kekecewaan (unacceptable quality).

Berdasarkan uraian tersebut di atas maka dapat disimpulkan bahwa kepuasan pasien adalah suatu ekspresi kejiwaan yang dirasakan pasien setelah membandingkan harapannya 
tentang suatu produk/jasa yang dirasakannya setelah menggunakannya.

\section{Hubungan Antara Kepuasan Pasien dengan Kesetian Pasien. \\ Kepuasan pasien merupakan} faktor yang menentukan bagi kelangsungan hidup usaha industri jasa kesehatan dalam hal ini rumah sakit.

Karena itu kepuasan dan ketidakpuasan pasien sebagai pelanggan rumah sakit dewasa ini mendapat perhatian khusus dari para penyelenggara rumah sakit.

Persaingan yang semakin ketat membuat banyak produsen dalam pemenuhan kebutuhan dan keinginan konsumen, menyebabkan setiap rumah sakit harus mengutamakan orientasi kepada kepuasan pasien sebagai tujuan utamanya. Komitmen ini terlihat dari semakin banyaknya rumah sakit yang menyertakan kepuasan pasien dalam iklan, visi, misi dan strategi pemasarannya.

Hanya rumah sakit yang memiliki komitmen inilah yang mampu beroperasi dalam situasi persaingan yang tajam dengan berbagai kebijakan dan teknologi yang selalu berubah serta berkembang secara pesat. Sehingga hanya rumah sakit seperti uraian di atas yang mampu mempertahankan kelangsungan hidupnya bahkan dapat tumbuh dan berkembang.

Seluruh aktivitas rumah sakit harus terus dilaksanakan sehingga seluruhnya mengarah pada usaha menciptakan kepuasan pada pasien sebagai pelanggan rumah sakit.

Sebagai pemberi jasa rumah sakit dituntut untuk dapat membuat jasa seperti yang diharapkan oleh pasien. Sehingga keputusn tentanng apa dan berapa yang harus ditawarkan kepada pasien tidak lagi berada ditangan rumah sakit tetapi mutlak ditangan pasien. Oleh karena itu bagi rumah sakit yang ingin memperoleh keuntungan jangka panjang, tidak ada jalan lain selain meberikan jasa pelayanan yang sesuai harapan pasien terutama dari segi kualitas pelayanan. Sehingga tercapai suatu kepuasan di kalangan pasien.

Berdasarkan uraian diatas diduga terdapat hubungan positif anatara kepuasan pasien dengan kesetiaan pasien.

\section{Metodologi Penelitian}

Penelitian ini menggunakan Survei dengan pendekatan korelasional yang mencari hubungan antara kepuasan dengan kesetiaan pasien pada bagian rawat inap rumah sakit Internasional Bintaro Tangerang.

Populasi dalam penelitian ini adalah pasien rawat jalan di bagian jantung. Sedangkan populasi terjangkaunya adalah pasien rawat jalan pada bagian jantung yang jumlahnya dalam 1 (satu) bulan rata-rata 300 orang.

Analisis data yang digunakan dalam penelitian ini adalah: regresi sederhana 


\section{Hasil Penelitian}

Berdasarkan dari hasil penelitian ditemukan bahwa: Persamaan regresi antara Kepuasan Pasien $(X)$ dengan Kesetiaan pasien (Y) adalah $\hat{Y}=89.97+0.32 \times 2$. Sehingga dapat disimpulkan bahwa persamaan regresi $\hat{Y}=89.97+0.32$ X2 signifikan dan linear. Maka persamaan regresi tersebut adalah perubahan satu unit pada kepuasan pasien $(X)$ akan diikuti oleh 0.32 unit pada kesetiaan pasien $(Y)$ pada arah yang sama dengan konstanta sebesar 89.97.

Koefisien korelasi sederhana kedua variabel adalah korelasi ry $2=$ $0.32(a=0.01)$ dan determinasinya sebesar $r^{2} y 2=0.10$. Ini berarti bahwa $10 \%$ variasi yang terjadi pada kesetiaan pasien dapat ditentukan oleh Kepuasan Pasien (X).

Koefesiensi korelasi parsial antara kedua variabel tersebut yaitu Kepuasan Pasien dengan kesetiaan pasien adalah ry2.1 $=0.21$. Berdasarkan uji signifikansi tersebut dapat disimpulkan bahwa dengan mengontrol variabel Mutu Pelayanan Rumah Sakit (X1) ternyata tidak terdapat hubungan positif antara variabel kepuasan dengan kesetiaan pasien.

\section{Kesimpulan}

Berdasarkan dari tujuan penelitian, yaitu ingin mengetahui hubungan antara Kepuasan Pasien dengan Kesetiaan Pasien berdasarkan hasil pengolahan dan analisis data, serta pengujian hipotesis, dapat disimpulkan bahwa terdapat hubungan yang positif antara Kepuasan Pasien dengan Kesetiaan Pasien yang dijelaskan oleh koefisien korelasi sebesar 0.32 dan kontribusi Kepuasan Pasien sebesar 0.10 melalui persamaan regresi $\hat{Y}=89.97+0.32 X 2$. Hal ini berarti meningkat atau menurunnya satu unit Kepuasan Pasien akan diikuti kenaikan dan penurunan Kesetiaan Pasien rata-rata 10\%.

\section{Daftar Pustaka}

Aker David A. Manajemen Ekuites Merek, Terjemahan Aris Ananda. Jakarta: Penerbit Mitra Utama, 1977

Alma Buchari, Manajemen Pemasaran \& Pemasaran Jasa, Bandung: Penerbit Alfa Beta,1992

Azwar Azul. Program Menjaga Mutu Pelayanan Kesehatan, Aplikasi Prinsip Lingkaran Pemecahan Masalah. Jakarta: Yayasan Penerbit IDI,1994

Biran Zainul, et.al. Psikologi Sosial. Jakarta: Penerbit Karunika Universitas Terbuka,1986

Cross Richard \& Smith Janet. Customer Bonding: Pathway to Lasting Costumer Loyalty. Lincolnwood, Illionis: NTC Bussiness Book, 1995.

Departemen Kesehatan Republik Indonesia, Peraturan Menteri Kesehatan Republik Indonesia Nomor 920/1986, Tentang Pelayanan Kesehatan Rumah Sakit Swasta di Bidang Medik. Jakarta: Depkes,1983 
Donabedian, Exploration in Quality Assesment and Monitoring health Administration. Michigan, Press annn Arbor, 1980.

Engel F James., Roger D. Blackwell, and Paul F. Miniard. Customer Behavior, Sixth Edition Orolondo: The Dryden Press, International Edition, 1990.

Gaspersz Vincent. Manajemen Kualitas Penerapan KonsepKonsep Kualitas Dalam Manajemen Bisnis Total. Jakarta: Yayasan Indonesia Emas dan Penerbit PT Gramedia Pustaka Utama,1997.

Hardjosoedarmo Soewarno. DasarDasar Total Quality Management. Yogyakarta: Andil 1992.

Indah dan Hartono. Trend Customer Satisfaction. Segi Majalah Swa, Desember 1993.

InfoBank Bonus. Pengembangan Produk di Era Globalisasi. Majalah InfoBank, Nomor 190, Oktober 1995.

Kartajaya Hermawan. Total Quality Service: Butuh Komitmen Total. Sigi Majalah Swa, Edisi Desember,1993.

Kotler Philip.

Manajemen Pemasaran. Terjemahan Ancella Anitawati Hermawan Jakarta: Penerbit Salemba Empat,1995.

Lou dan D.L. dan A.J.D Bitta. Consumer Behavior: Concept and Applications. New York:
MC. Graw-Hill Book Company, 1988.

Lovelock Cristoper H. Service Marketting. Englewood Cliffs, New Jersey, Prentice Hall,1991.

Mulyadi Bagus, dkk. Standar Pelayanan Rumah Sakit. Jakarta: Depkes, Ditjen Yanmed, DIT. Rumah Sakit Umum dan Pendidikan,1996.

Peraturan Menteri Kesehatan Republik Indonesia No. 920/Men.Kes/Per/XII/1986, Tentang Upaya Pelayanan Kesehatan Swasta di bidang Medik.

Rukmita Adi Isbandi. Psikologi Pekerjaan Sosial dan IImu Kesejahteraan Sosial: DasarDasar Pemikiran. Jakarta: PT Raja Grafindo Persada,1994.

Sakaria Mona, Manajemen Ekspetasi Untuk Meningkatkan Mutu Layanan. Majalah Forum Manajemen Prasetya Mulya, Nomor 60,1995.

Soeprapto A.S.administrasi rumah sakit. Jakarta: CV. Barata Jaya, 1985.

Spegell, D. allen. Review of the factor effecting the Quality and Acceptability of health care. New York, SP Medicall and Scintific book, 1980.

Taufik. Bukan Sekedar Hadiah Besar. Majalah Info Bank, Nomor 205, Januari 1997.

Tjiptono Fandy. Strategi Pemasaran. Yogyakarta: Penerbit Andi Offset, 1997. 
Tjiptono Fandy. Total Quality Management. Yogyakarta: Penerbit Andi Offset, 1995.

Warren W William. Relative Importance of Personal (Non Marketer) and Non Personal (Market Dominated) Information Sources in Adopting a Service Product. Kennet D. Bahn, Development in Marketing Siensi, 1988, Edisi ke 11, p. 345-349 Dikutip oleh
Mona Sakaria, Mengelola Ketidakpuasan Nasabah dalam Konteks Pemasaran Layanan. Majalah Forum Manajemen Prasetya Mulya, Nomor 60,1995.

Zeithaml Valarie A., A. Parasumen, Leonard I. Berry. Delivering Quality Service Balancing Customer Perceptions and Expectations. New York: Free Press, 1990. 